\title{
Stability and Control of Retracement Channels in Thin Seam Working Faces with Soft Roof
}

\author{
Binbin Qin, ${ }^{1}$ Fulian He, ${ }^{1,2}$ Xiaobing Zhang, ${ }^{3}$ Xuhui Xu, ${ }^{1}$ Wei Wang $\left(\mathbb{D},{ }^{3}\right.$ Liang Li $\mathbb{D},{ }^{1}$ \\ and Chen Dou ${ }^{4}$ \\ ${ }^{1}$ School of Energy and Mining Engineering, China University of Mining and Technology (Beijing), Beijing 100083, China \\ ${ }^{2}$ Beijing Key Laboratory for Precise Mining of Intergrown Energy and Resources, (CUMTB), Beijing 100083, China \\ ${ }^{3}$ Safety and Emergency Management Research Center, Henan Polytechnic University, Henan 454003, China \\ ${ }^{4}$ Xuehu Coal Mine, Shenhuo Group, Henan 476643, China
}

Correspondence should be addressed to Wei Wang; wangwei@hpu.edu.cn

Received 1 July 2021; Accepted 30 August 2021; Published 13 September 2021

Academic Editor: Jun Wang

Copyright ( 2021 Binbin Qin et al. This is an open access article distributed under the Creative Commons Attribution License, which permits unrestricted use, distribution, and reproduction in any medium, provided the original work is properly cited.

To reduce the risk of roof falling and rib spalling during equipment retracement in thin coal seam faces with soft roofs, the 25070 working face of Xuehu Coal Mine was taken as the research object, and theoretical analysis, numerical simulation, and field practice methods were used. Under different space relationships between retracement channels and main roof fracture, the load of hydraulic supports was quantitatively analyzed. The relationship between the working resistance of the hydraulic support and the sinking rotation angle of the immediate roof was analyzed, and a reasonable time for the arrangement of the retracement channel was determined. The sublevel excavation technology and the combined support technology of roof anchor cables and coal rib anchors were proposed. The field application shows that the falling height and rate of movable prop of the hydraulic supports, working resistance of the hydraulic supports, and the roof subsidence all meet the requirements of safety production during the terminal mining period, and the surrounding rock control effect of retracement channel was determined to be good. The safe and efficient mining of the coal mine is ensured, and the research results can provide guidance for similar working faces.

\section{Introduction}

The retracement of working face equipment is an important link of coal mine mining [1]. The retracement channel connected with the working face needs to be set in the stopping line for the retracement of working face equipment, which is different from normal mining. The characteristics of large sections, equipment, complex technology, and close proximity to the rear gob determine that only by reasonably setting and supporting the retracement channel, the working face equipment can be safely and quickly retraced [2]. In the working face of a thin coal seam with a soft roof, the soft roof easily causes roof falling (leakage) and support failure in the retracement space because of the low mining height. Because the roof is not well supported, it is prone to the overall sliding of the overlying strata and impact on the retracement channel, resulting in the coal rock dynamic disaster.
Therefore, reasonable excavation and support technology is particularly important [3-5]. Generally, the layout methods of retracement channels used in coal mines include the preexcavation double retracement channel [6-8], pre-excavation single retracement channel $[8,9]$, and no pre-excavation retracement channel $[10,11]$. Among them, no pre-excavation retracement channel technology has been widely used due to the advantages of flexible selection of the stopping line. In research on the reasonable location of the retracement channel, the influence of the main roof fracture of the retracement channel without pre-excavation on the retracement channel was qualitatively analyzed, and the principle of "top wall cooperative control" of the retracement channel was proposed [12-14]. A roof structure mechanical model of the pre-excavation retracement channel was constructed, and the variation law of the working resistance of the hydraulic support was analyzed. The failure 
characteristics and stress distribution of the lower retracement channel in the condition of close-distance doublethick coal seam mining and the control strategy of "highpressure water jet + asymmetric high-strength cable-beam net + three-hole anchor cable group + roof grouting" were provided to ensure the stability of the channel [1]. In theoretical research on the support technology of retracement channels, a structural mechanical model of anchor beams for roof reinforcement support of retracement channels was established [15-17]. With respect to roof stability research above the retracement channel during the retracement of equipment, through the analysis of the fracture morphology of the immediate roof and the main roof above the retracement space, a reasonable retracement mode of equipment was proposed $[18,19]$. In addition, other scholars and relevant researchers have also carried out beneficial exploration and practice on control technology [20]. However, quantitative analysis of the impact of main roof breaking and rotation deformation on the retracement channel without pre-excavation is limited, and research on the excavation process and the stability of the retracement channel under special conditions is lacking. Based on this, this paper, taking the thin seam working face with soft roof in Xuehu Coal Mine as the research object, quantitatively analyses the stability of surrounding rock under different spatial locations of the retracement channel and the main roof fracture, determines the reasonable location of the retracement channel, and puts forward the targeted retracement channel excavation and support scheme, which has a good field application effect.

\section{Engineering Background}

Taking the 25070 working face of a typical soft roof thin coal seam in the Xuehu Coal Mine as the research site, the Xuehu Coal Mine is located in northern Yongcheng City, Henan Province, China, as shown in Figure 1. The No. 2 coal seam of the Shanxi Group is mainly mined, and it has the risk of coal and gas outburst. The 25070 working face is located in the east of 25 mining district. The ground elevation is $+37.0 \mathrm{~m}$, and the working face elevation is $-793 \mathrm{~m} \sim-711 \mathrm{~m}$. The distribution of rock properties of the roof and floor is shown in Figure 1. The single longwall full-mechanized mining method is adopted in the 25070 working face, with full-height mining at one time and full caving roof management. The thickness of the coal seam in the 25070 working face is $0-3.7 \mathrm{~m}$, and the average thickness is $2.3 \mathrm{~m}$. The structure of the coal seam is simple, and the dip angle of the coal seam is $2^{\circ}-15^{\circ}$. The strike length is $1132 \mathrm{~m}$, and the dip length is $175 \mathrm{~m}$. There are 118 zy6600/14/32 hydraulic supports used for roof support.

The ZKXG30 mine-used borehole imager was used to observe the internal structure of the borehole directly above the hydraulic support during the weighting and nonweighting of the periodic weighting of the 25070 working face of Xuehu Coal Mine, as shown in Figure 2.

The main roof breaks and deforms when the 25070 working face is weighting. The immediate roof directly is extruded by the main roof and the hydraulic support. The closer the distance to the canopy of the hydraulic support, the more serious the rock mass damage. During nonweighting, the hole wall deforms slightly at the initial depth. As the depth of the hole increases, the deformation of the hole wall decreases until the main roof is not significantly damaged. When the working face is weighting, the immediate roof is broken compared with nonweighting and the control of the roof of the working face is more difficult.

\section{Analysis of the Influence of Main Roof Fracture on Support Load}

As the working face excavation, the main roof is periodically broken and deformed by rotation, and its different locations will inevitably cause different levels of ground pressure [21]. Owing to the low mining height and high mechanization, the 25070 working face of Xuehu Coal Mine has the characteristics of fast excavation speed, high mining intensity, and a soft roof. When the working face is close to the stopping line, an undercover of approximately $0.7 \mathrm{~m}$ is required to expand the height of the equipment retracement space. The increase in height leads to an increase in the main roof rotation angle above the working face, and its extrusion force on the working face hydraulic support increases accordingly, which affects the safe retracement of the working face equipment.

According to the difference between the fracture of the main roof key block $A$ and $B$ and the space location of the retracement channel, it can be divided into four situations: the key block $A$ and $B$ fracture above the gob, above the hydraulic support, above the retracement channel, and above the solid coal, as shown in Figure 3.

(1) The fracture of key blocks $A$ and $B$ are located above the gob, as shown in Figure 3(a). The main roof is a cantilever beam structure fixed at one end. Since the immediate roof is a rock mass that cannot be balanced by itself, the hydraulic support only bears load of the immediate roof at this time. It can be calculated as follows:

$$
Q_{0}=l_{k} d h_{z} \gamma
$$

where $Q_{0}$ is the load of the hydraulic support, $\mathrm{MPa} ; l_{\mathrm{k}}$ is the face-to-gob distance of the hydraulic support, $\mathrm{m} ; d$ is the width of the hydraulic support, $\mathrm{m} ; h_{\mathrm{z}}$ is the thickness of the immediate roof, $\mathrm{m}$; and $\gamma$ is the bulk density of the immediate roof, $\mathrm{MN} / \mathrm{m}^{3}$.

(2) When the fracture of key blocks $A$ and $B$ are above the hydraulic support, above the retreat channel and above the solid coal, after key block $B$ is broken, it rotates, which exerts an extrusion effect on the immediate roof $[22,23]$, as shown in Figures 3(b)$3(\mathrm{~d})$. The immediate roof transmits the self-weight load and the extrusion force generated by the main roof rotation to the hydraulic support, and the load of the hydraulic support increases, which is likely to cause support failure. During the period of weighting, the immediate roof is in a relatively 


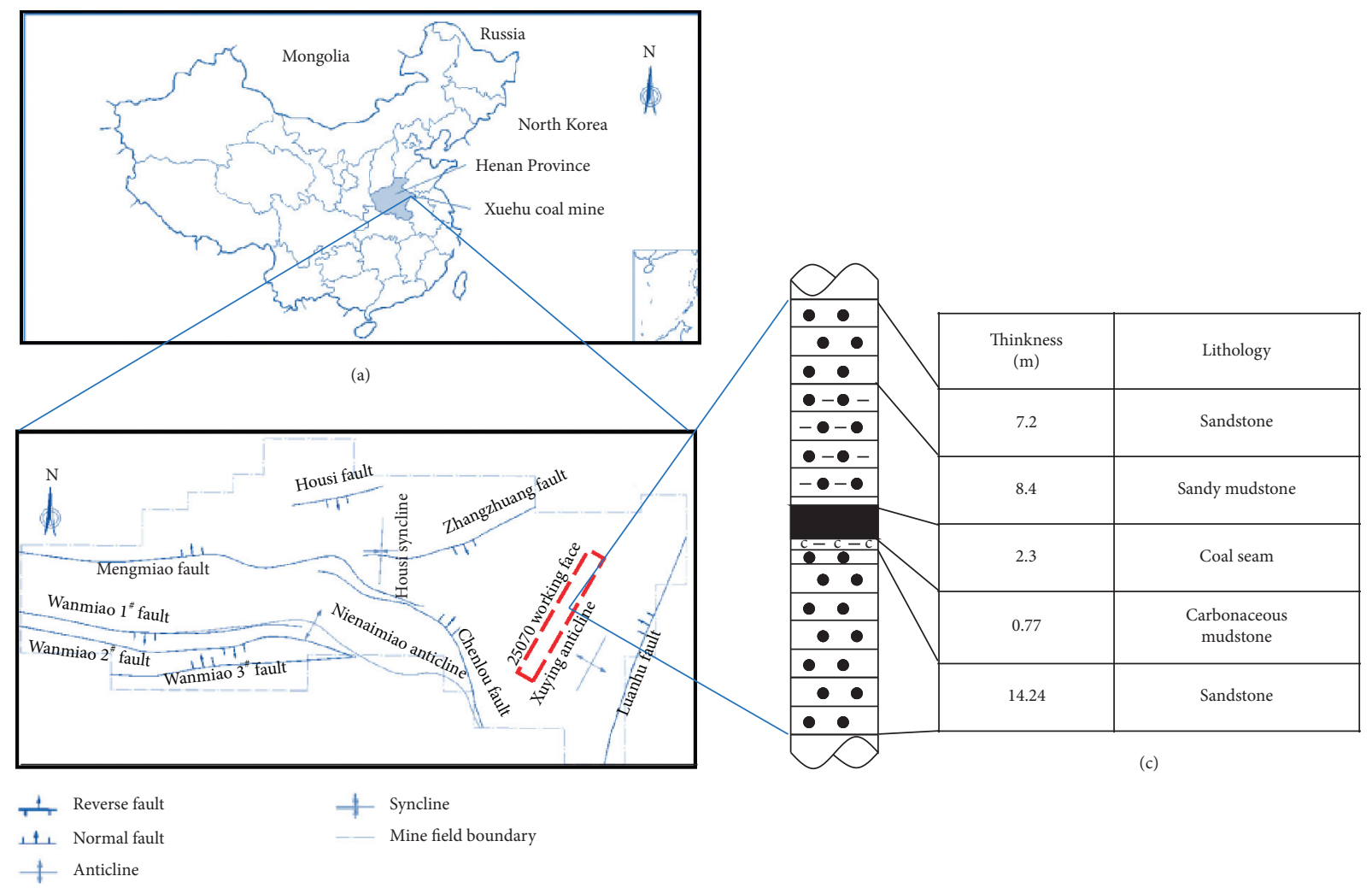

(b)

Figure 1: Location map of the Xuehu Coal Mine.

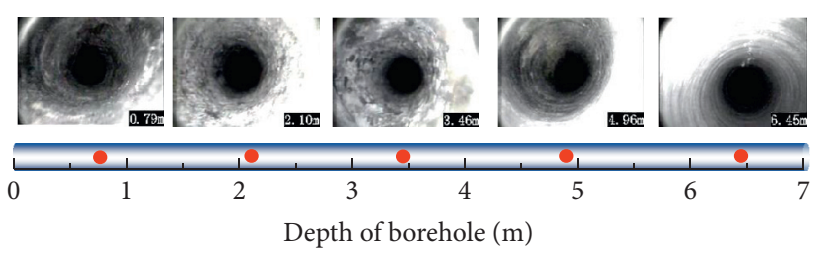

(a)

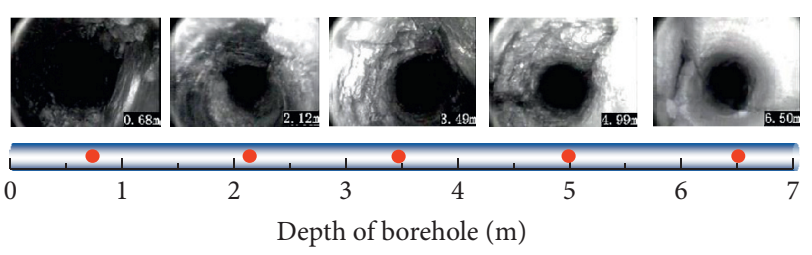

(b)

FIgURE 2: Inside view of the 25070 working face roof. (a) During weighting. (b) During nonweighting.

broken state. The immediate roof can be regarded as the process of the extrusion and compaction of the main roof and the hydraulic support, and the rock mass is the fractured structure. The relationship between stress and strain satisfies the following formula:

$$
\sigma_{z}=\mu \varepsilon_{z}^{n}
$$

where $\sigma_{z}$ is the immediate roofing stress, $\mathrm{MPa} ; \mu$ is the immediate roof compaction coefficient, $\mathrm{GPa} ; \varepsilon_{z}$ is the immediate roof strain; and $n$ is the immediate roof compaction index.

The strain expression of the immediate roof extrusion process can be calculated using the following formula [24-28]:

$$
\varepsilon_{z}=\frac{x \sin \left(\theta-\theta_{1}\right)}{h_{z}}
$$

where $x$ is the distance from the main roof to the break line, $\mathrm{m} ; \theta$ is the given deformation rotation angle of the main roof, ; and $\theta_{1}$ is the immediate roof sinking rotation angle, .

The immediate roof extrusion force can be calculated using the following formula:

$$
M=a \int_{0}^{1} \sigma_{z} \mathrm{~d} x,
$$

where $a$ is the width of the immediate roof rock block, $m$ and $l$ is the length of the immediate roof rock block, $\mathrm{m}$.

At this time, the hydraulic support load can be calculated using the following formula: 


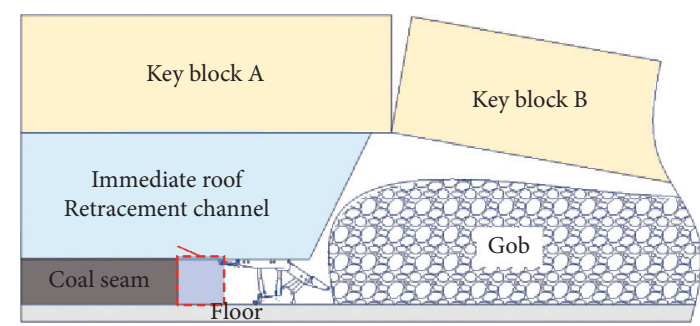

(a)

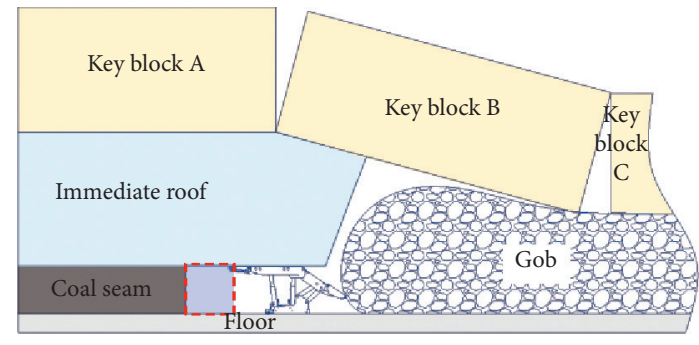

(c)

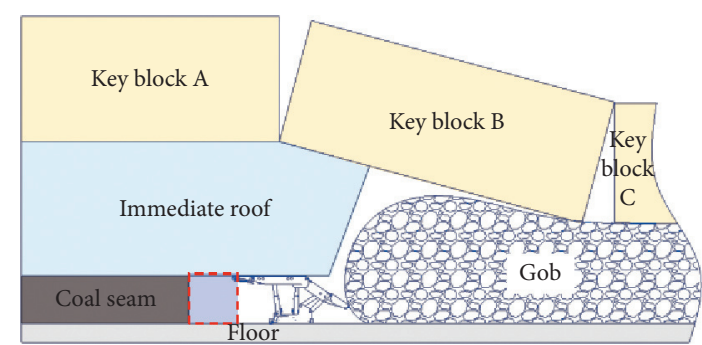

(b)

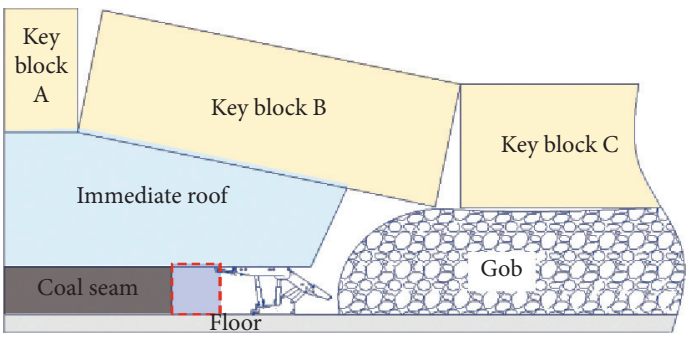

(d)

Figure 3: Schematic diagram of the location of the main roof fracture and the retracement channel. (a) Above the gob. (b) Above the hydraulic support. (c) Above the retracement channel. (d) Above the solid coal.

$$
Q_{1}=Q_{0}+M \text {. }
$$

According to formulas (1)-(5), the load of the hydraulic support in the retracement channel can be calculated using the following formula:

$$
Q= \begin{cases}l_{k} d h_{z} \gamma, & \theta=0, \\ l_{k} d h_{z} \gamma+\frac{a \mu l^{n+1} \sin \left(\theta-\theta_{1}\right)}{(n+1) h_{z}}, & \theta \neq 0, \theta \geq \theta_{1},\end{cases}
$$

According to the actual situation of the 25070 working face in the Xuehu coal mine, the face-to-gob distance of the hydraulic support is $5.2 \mathrm{~m}$ and the width of hydraulic support is $1.43 \mathrm{~m}$. The thickness of the immediate roof is $8 \mathrm{~m}$, and the volume weight of the immediate roof is $0.025 \mathrm{MN} /$ $\mathrm{m}^{3}$. The compaction coefficient of the immediate roof is $1 \mathrm{GPa}$, and the compaction index of the immediate roof is 3 . The given deformation rotation angle of the main roof is $8^{\circ}$. The width of the immediate roof block is $1.43 \mathrm{~m}$, and the length of the immediate roof block is $5.2 \mathrm{~m}$. When the fracture of the main roof is different from the space location of the retracement channel, the extrusion degree of the main roof to the immediate roof above the hydraulic support is different, which leads to the different sinking rotation angle of the immediate roof. The relationship between the load of the hydraulic support and the sinking rotation angle of the immediate roof is shown in Figure 4.

In the case of given deformation of the main roof, as the location of the fracture moves from the solid coal to the gob, the degree of extrusion of the main roof and the hydraulic support to the immediate roof gradually weaken. The difference between $\theta$ and $\theta_{1}$ gradually decreases, and the load of the hydraulic support gradually decreases until the fracture reaches the rear of the hydraulic support and the roof above

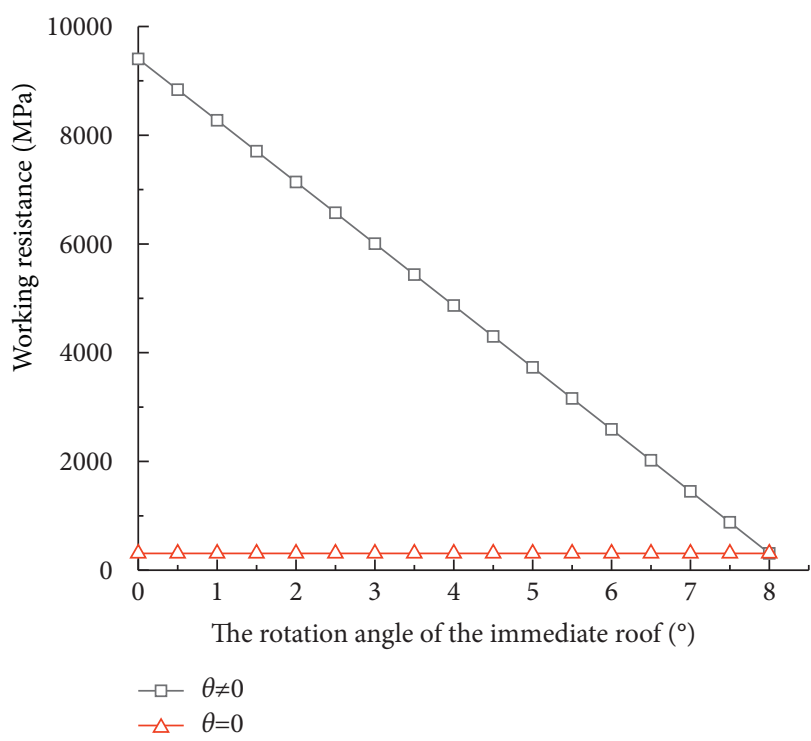

FIGURE 4: The relationship between the load of the hydraulic support and the sinking rotation angle of the immediate roof.

and in front of the working surface has not yet broken. At this time, the load of the hydraulic support is the smallest.

Under the conditions shown in Figures 3(b) and 3(c), if the initial working resistance of the hydraulic support is insufficient or the retracement channel is not supported in time, the main roof key block B easily slides and loses stability, and the dynamic load increases. The load increases rapidly, especially during the retracement of the hydraulic support. A large area of overhang appears on the roof, and the risk of slipping is further increased. In Figure 3(d), the fracture is above the solid coal, so the rotation of key block $B$ will also extrude the coal rib of the 
retracement channel, resulting in large deformation and spalling of the coal rib.

When the main roof fracture is above the gob, the roof structure of the working face is relatively stable, and the load on the hydraulic support is the smallest. Arranging the retracement channel at this location is beneficial to the control of the surrounding rock and the safe and smooth retracement of the equipment.

The main roof fracture above the gob must meet the step distance of periodic weighting to be greater than the sum of the width of the retracement channel and the length of the hydraulic support.

$$
L>(1+\lambda)\left(L_{\mathrm{r}}+L_{\mathrm{s}}\right),
$$

where $L$ is the periodic weighting step, $\mathrm{m} ; \lambda$ is the surplus coefficient, usually $0.2-0.3 ; L_{\mathrm{r}}$ is the width of the retreat channel, $\mathrm{m}$; and $L_{\mathrm{s}}$ is the total length of the hydraulic support, $\mathrm{m}$.

According to the on-site investigation, the periodic weighting step of the 25070 working face of Xuehu Coal Mine is $15 \mathrm{~m}$. The width of the retracement channel is $2.5 \mathrm{~m}$, and the length of the hydraulic support is $4.4 \mathrm{~m}$. The surplus coefficient is 0.3 . The result shows that $15 \mathrm{~m}>8.97 \mathrm{~m}$. The 25070 working face can meet the main roof fracture above the gob, achieving the purpose of safe and smooth retracement of equipment.

Therefore, the time to arrange the retracement channel in the 25070 working face is reasonable when the main roof fracture is above the gob. The location is shown in Figure 3(a).

\section{Surrounding Rock Control Technology}

4.1. Difficulties and Ideas of the Surrounding Rock Control. The reasonable location of the retracement channel can ensure that the load of the hydraulic supports is in the minimum state during the removal of the equipment. The characteristics of low mining height and the soft roof of coal seam are recognized by Xuehu Coal Mine, and the difficulties of surrounding rock control of the retracement channel are as follows:

(1) The extrusion force caused by the "given deformation" of the main roof rotation is transmitted to the hydraulic support through the immediate roof; if the roof subsidence is too large, the hydraulic support will be crushed and unable to move.

(2) In front of the hydraulic support, the roof exposure area of the retracement channel is large, the roof is soft, and there is a high probability of roof caving (roof leakage) in the retracement channel.

(3) Soft coal with a thickness of $0.3-0.5 \mathrm{~m}$ in the coal seam reduces the strength of the coal mass, and the rib of the retracement channel easily deforms and fails.

(4) After the hydraulic supports are removed from the original location, the exposed area of the roof increases further. Along the direction of the working face, the main roof breaks and rotates. The load of the hydraulic supports is further increased in the area where the hydraulic support does not move out.

Based on this, the surrounding rock control ideas of the retracement channel in the Xuehu coal mine are as follows:

(1) The location of the retracement channel should be designed under the cantilever beam of the main roof, and the load on the hydraulic supports is the minimum at this time

(2) The artificial sublevel excavation technology is used to form the retracement channel to reduce the disturbance effect of the excavation retracement channel on the roof and coal body

(3) The hydraulic supports are strictly managed, and the hydraulic support has enough initial working resistance to prevent bed separation of the roof

(4) The surrounding rock of the retracement channel is supported in time to ensure the integrity of the surrounding rock and improve the loading capacity of the surrounding rock

(5) After the equipment is removed, the roof subsidence and rib deformation in this area should be controlled, the pressure concentration of the roof should be relieved, and the ventilation system of the working face should be smooth

(6) After the excavation of the retracement channel, the main roof and its upper load are gradually transferred to the hydraulic support through the immediate roof, and it is necessary to speed up the retracement of equipment

4.2. The Scheme of the Excavation Retracement Channel. The retracement channel of the 25070 working face in the Xuehu Coal Mine is $2.8 \mathrm{~m}$ high and $2.5 \mathrm{~m}$ wide, and sublevel excavation technology is adopted, as shown in Figure 5. The process is as follows: (1) sublevel excavation; (2) temporary roof support; (3) permanent roof support; (4) rib support. The width of each excavation of the retracement channel is $4.5 \mathrm{~m}$. The excavation was carried out in groups at the same time, and the distance of each group was $15 \mathrm{~m}$. The requirement of "excavation one row and supporting one row in time" is strictly implemented. The face-to-tip distance of the temporary support is not more than $300 \mathrm{~mm}$. A $3.6 \mathrm{~m}$ long steel beam with a single hydraulic prop is used to the temporary support roof along the working face, and " 1 beam +3 columns" is required, as shown in Figure 5. Permanent support is carried out immediately after excavation of the retracement channel.

4.3. Effect Analysis of Excavation. FLAC3D software can simulate the mechanical problems of coal and rock masses in the process of underground mining. To analyze the influence of the sublevel excavation technology on the stability of the surrounding rock of the retracement channel, according to the surrounding rock distribution of the 25070 working face 


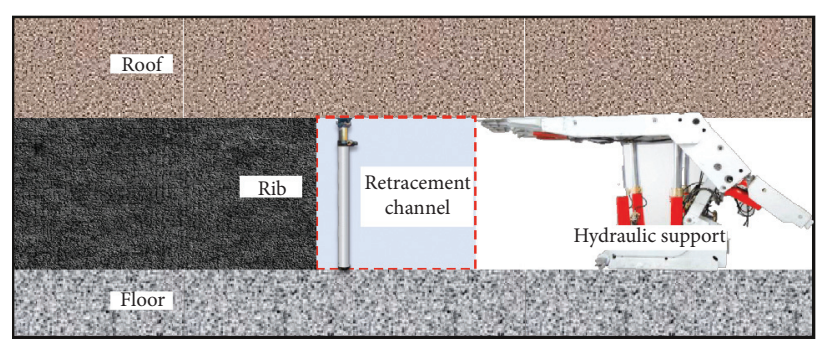

(a)

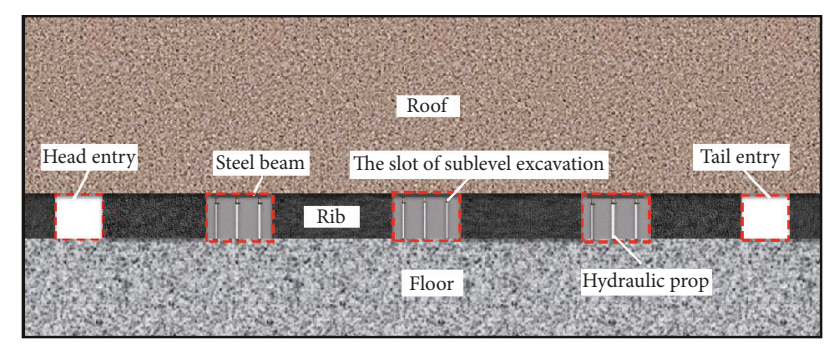

(b)

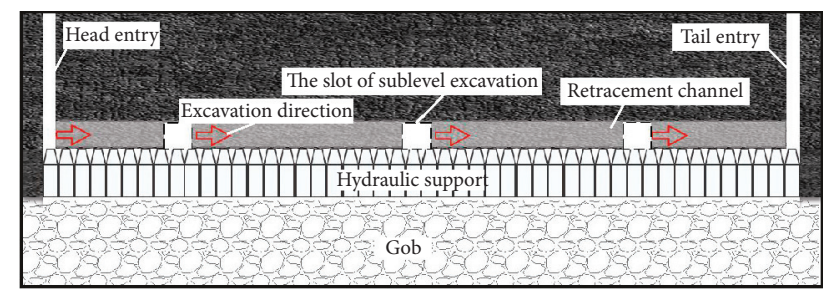

(c)

Figure 5: Excavation diagram of the retracement channel. (a) Lateral view. (b) Front view. (c) Top view.

in the Xuehu coal mine, a numerical model with a length, width, and height of $200 \mathrm{~m} \times 100 \mathrm{~m} \times 39 \mathrm{~m}$ was established by Flac3D.

The process of obtaining rock mechanical parameters was as follows: first, the coal and rock samples were collected in the 25070 working face. Second, the standard coal and rock samples for physical and mechanical properties testing were made, and the physical and mechanical parameters were tested in the laboratory. Third, the parameters in the numerical simulation were obtained. Owing to the difference between the testing environment in laboratory and the field environment, the parameters obtained in laboratory cannot be directly used in numerical simulation and need to be corrected $[29,30]$. The elastic modulus, cohesion, and tensile strength of coal and rock masses were 0.25 times the laboratory test results, while the Poisson's ratio is 1.2 times the laboratory test results. The parameters of the numerical model are shown in Table 1.

A vertical load of $15 \mathrm{MPa}$ was applied to the upper boundary of the model; the fixed horizontal displacements was applied to the horizontal boundary, and the fixed displacements was applied to the bottom. The Mohr-Coulomb failure criterion is adopted for the whole model. The initial horizontal in situ stress was 1.2 times in the $x$ - and $y$-axis directions. The distribution law of the vertical stress and displacement of the surrounding rock in the retracement channel of the sublevel excavation and the full excavation are simulated and compared. The simulation results are shown in Figures 6-9.

Five measuring lines are set at $0.5 \mathrm{~m}, 1.5 \mathrm{~m}, 2.5 \mathrm{~m}, 3.5 \mathrm{~m}$, $4.5 \mathrm{~m}$, and $5.5 \mathrm{~m}$ above the retracement channel from the roof. It can be seen from Figure 6 that

(1) The vertical stress in the gob is the smallest and gradually increases along the extraction advance direction of the working face until the peak value is reached at $4.5 \mathrm{~m}$ within the rib and then the vertical stress gradually decreases until it is the same as the original rock stress.

(2) Above the gob and retracement channel, the vertical stress increases with increasing height. In solid coal, the vertical stress decreases with increasing height. The peak stress decreases with increasing height, and it shows that the higher the location in the solid coal in front of the retracement channel is, the smaller the influence of mining is.

(3) The peak value of vertical stress of surrounding rock of the retracement channel of the sublevel excavation is lower than that of full excavation, and it shows that full excavation more easily causes the stress concentration of solid coal in front of the working face. It is not conducive to the stability of the retracement channel.

It can be seen from Figure 7 that

(1) The vertical displacement of the roof in the gob is the largest and gradually decreases along the extraction advance direction of the working face until vertical displacement in the solid coal in front of the working face gradually approaches 0

(2) The higher the height above the retracement channel is, the smaller the vertical displacement is

(3) The maximum vertical displacements of the roof above the retracement channel are $24 \mathrm{~mm}$ and $78 \mathrm{~mm}$ with sublevel excavation and full excavation, respectively, which shows that sublevel excavation can effectively reduce roof subsidence

The principal stress difference is the difference between the first principal stress and the third principal stress. The larger the principal stress difference is, the unbalanced the stress distribution of the rock (coal) mass and the rock (coal) mass more easily fails. It can be seen from Figure 8 that 
TABLE 1: The parameters of coal and rock mass in numerical simulation.

\begin{tabular}{lcccccc}
\hline Layer & Density $\left(\mathrm{kg} / \mathrm{m}^{3}\right)$ & Bulk modulus $(\mathrm{GPa})$ & Shear modulus (GPa) & Cohesion (MPa) & $\begin{array}{c}\text { Internal friction } \\
\text { angle }\left(^{\circ}\right)\end{array}$ & $\begin{array}{c}\text { Tensile strength } \\
(\mathrm{MPa})\end{array}$ \\
\hline Main roof & 2800 & 10.80 & 5.50 & 4.40 & 33 & 6.00 \\
Immediate roof & 1900 & 3.67 & 2.20 & 2.40 & 29 & 1.50 \\
Coal seam & 1426 & 2.40 & 1.10 & 1.50 & 26 & 1.00 \\
Floor & 2495 & 8.45 & 3.90 & 5.10 & 33 & 8.00 \\
\hline
\end{tabular}

Vertical stress (MPa)

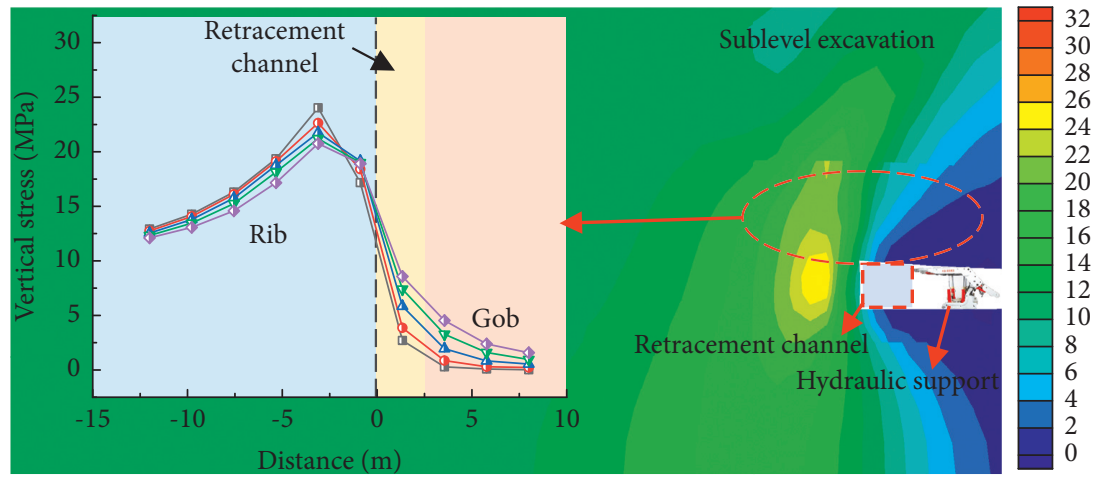

$$
\begin{aligned}
& \rightarrow 0.5 \mathrm{~m} \quad \rightarrow-3.5 \mathrm{~m} \\
& \rightarrow 1.5 \mathrm{~m} \quad \rightarrow-4.5 \mathrm{~m} \\
& \rightarrow-2.5 \mathrm{~m}
\end{aligned}
$$

Vertical stress (MPa)

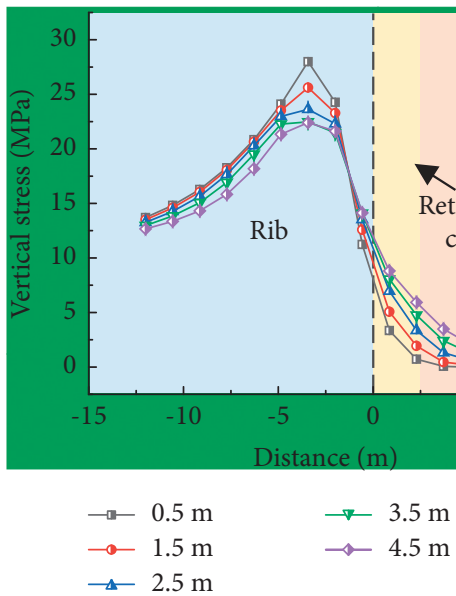

Figure 6: Comparison of the vertical stress distribution.

(1) Along the extraction advance direction of the working face, the principal stress difference gradually increases from the gob to the solid coal and then gradually decreases. The farther the location in the solid coal is from the rib, the smaller the principal stress difference is, and it tends to be stable.

(2) With a higher location, the peak value of the principal stress difference tends to shift to the far part of solid coal.

(3) The peak value of the principal stress difference of the sublevel excavation of the retracement channel is lower than that of the full excavation. This indicates that the surrounding rock of the retracement channel is more likely to fail.

(4) The peak values of the principal stress difference of the sublevel excavation and full excavation are $1 \mathrm{~m}$ and $2.5 \mathrm{~m}$ away from the coal rib, respectively. The peak value of the principal stress difference of full excavation is far from the solid coal rib, its failure depth is greater, and it is more difficult to support the surrounding rock of the retracement channel.

Figure 9 shows that the horizontal displacement of the middle of the solid coal rib of the retracement channel is greater than that of the top and bottom, and the maximum 
Vertical displacement $(\mathrm{m})$
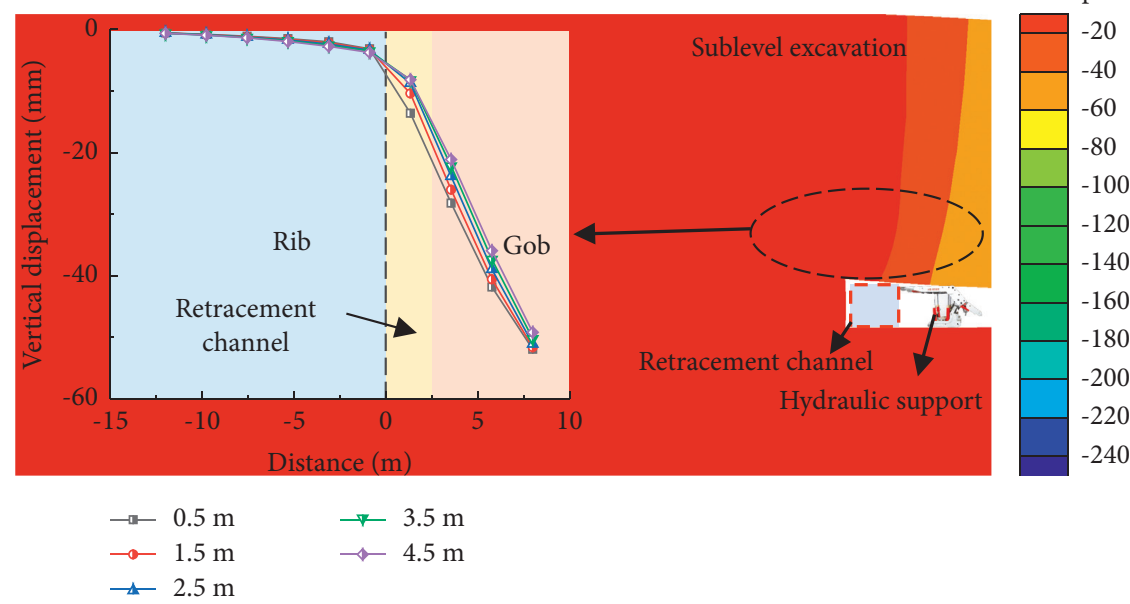

Vertical displacement $(\mathrm{m})$
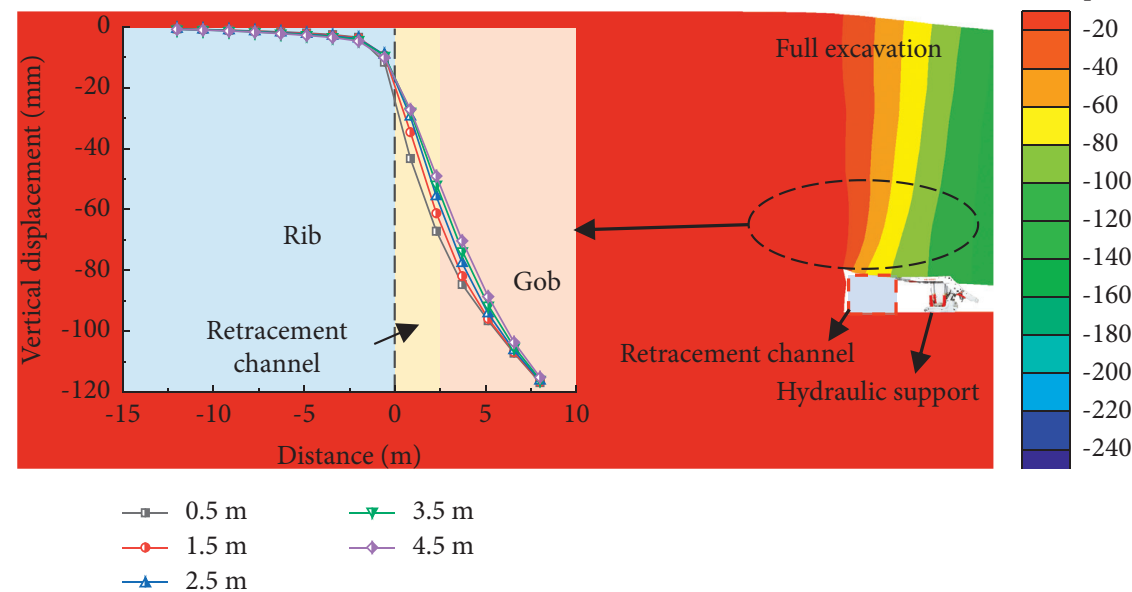

Figure 7: Comparison of the vertical displacement distribution.

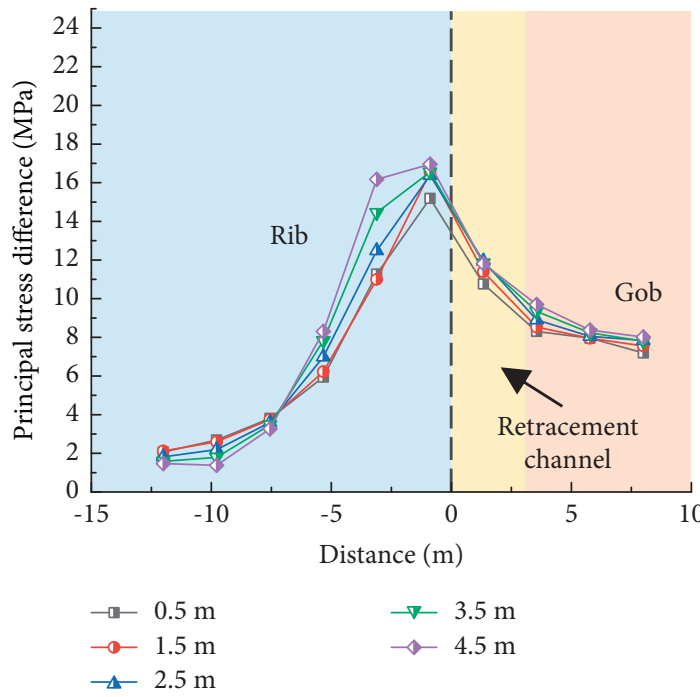

(a)

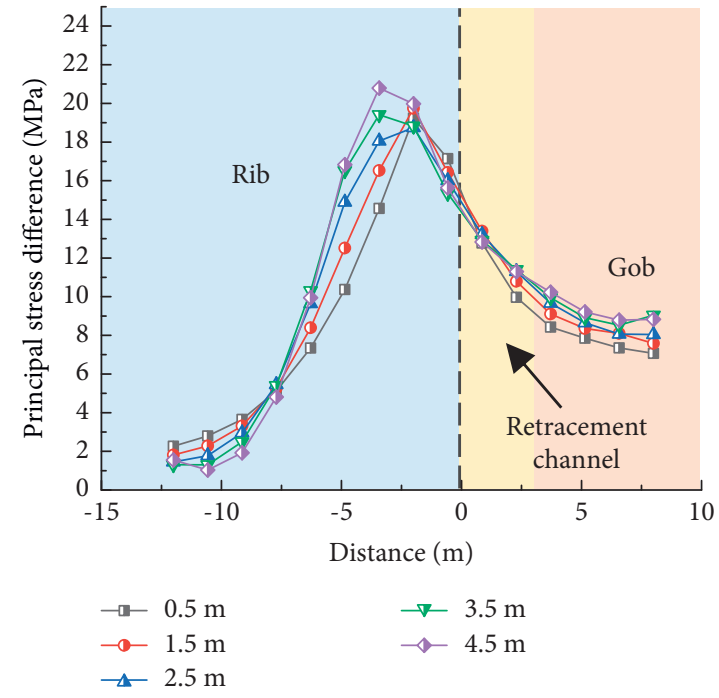

(b)

FIGURE 8: Comparison of the principal stress difference distribution. (a) Sublevel excavation. (b) Full excavation. 


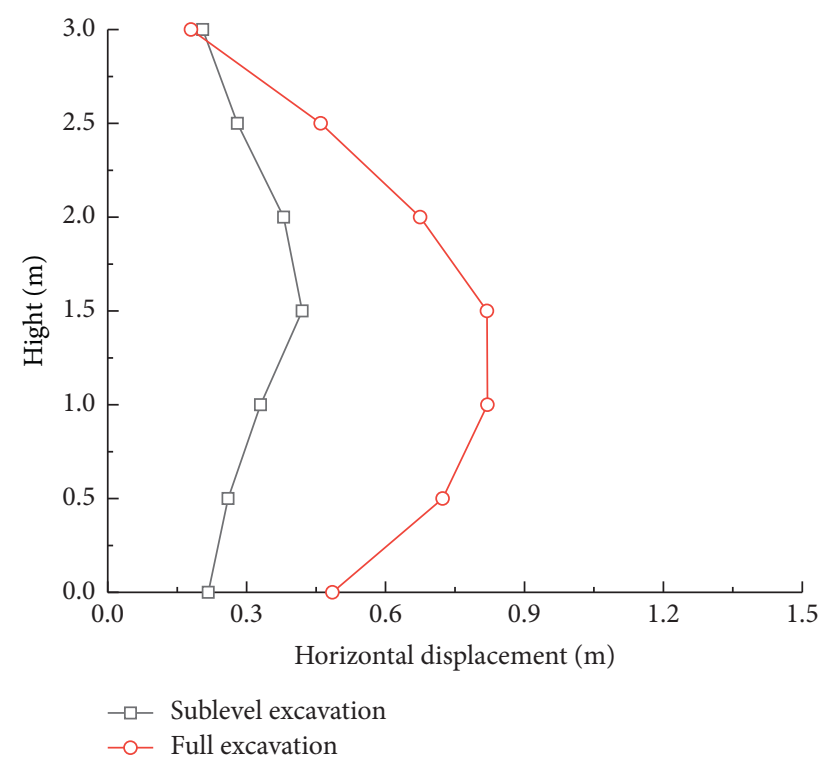

Figure 9: Comparison of the horizontal displacement of the rib.

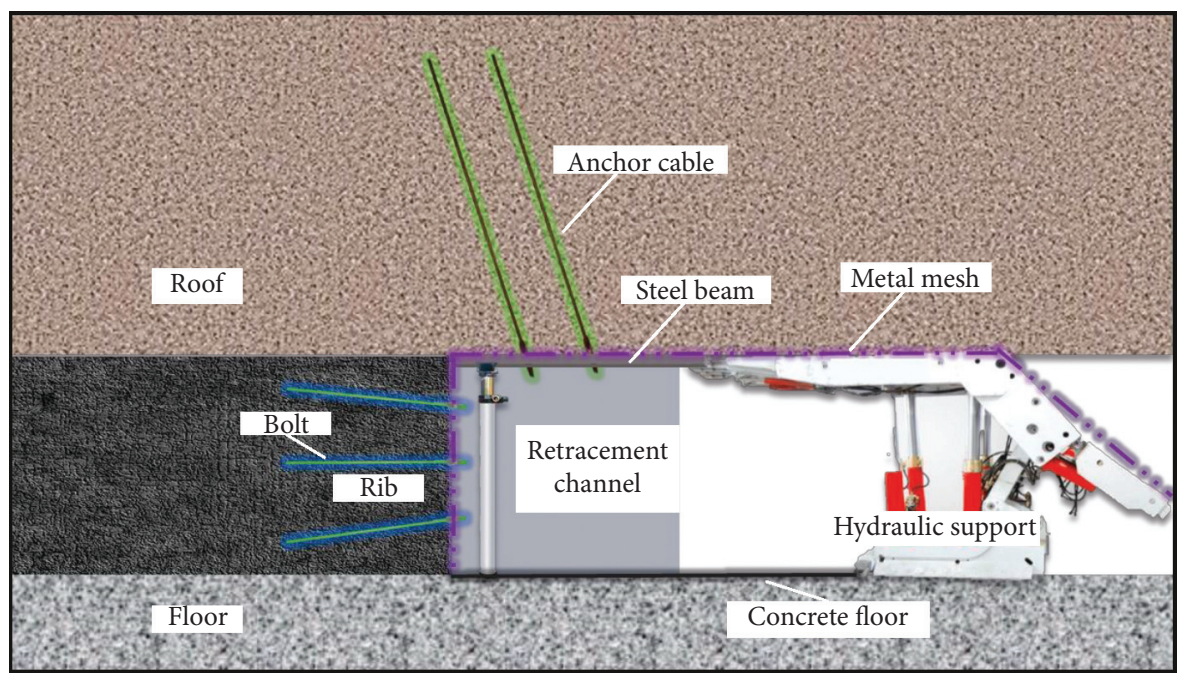

Figure 10: Diagram of support for the retracement channel.

horizontal displacement of the sublevel excavation is $0.42 \mathrm{~m}$ smaller than that of the full excavation. The deformation of the coal rib is more severe with full excavation, and the coal rib is more difficult to support.

\section{Field Engineering Practice}

5.1. Permanent Support Scheme. Field practice was carried out in the 25070 working face of the Xuehu coal mine. According to the actual conditions, the "steel beam + anchor cable + rhombic metal mesh" is used for the permanent support of the roof of the retracement channel, the solid coal rib is supported by a "high-strength bolt + diamond metal mesh," and concrete is poured to harden the floor, as shown in Figure 10.
5.2. Application Effect Analysis. Five measuring stations are set in the working face, which are $30 \mathrm{~m}, 60 \mathrm{~m}, 90 \mathrm{~m}, 120 \mathrm{~m}$, and $150 \mathrm{~m}$ away from the joint of the working face and the head entry. The monitoring time is from 80 hours before excavation to 120 hours after excavation, and the monitoring contents include the falling height of the movable prop of the hydraulic supports, the working resistance of the hydraulic supports, and the subsidence of the roof.

(1) As shown in Figure 11, the falling height of the hydraulic support movable prop increases with time and the average falling height of the hydraulic support movable prop is $66.8 \mathrm{~mm}$. Among them, the falling height of the movable prop of station \#3 is the largest, and $95 \mathrm{~mm}$ was reached before the equipment was retraced. The falling height of the 


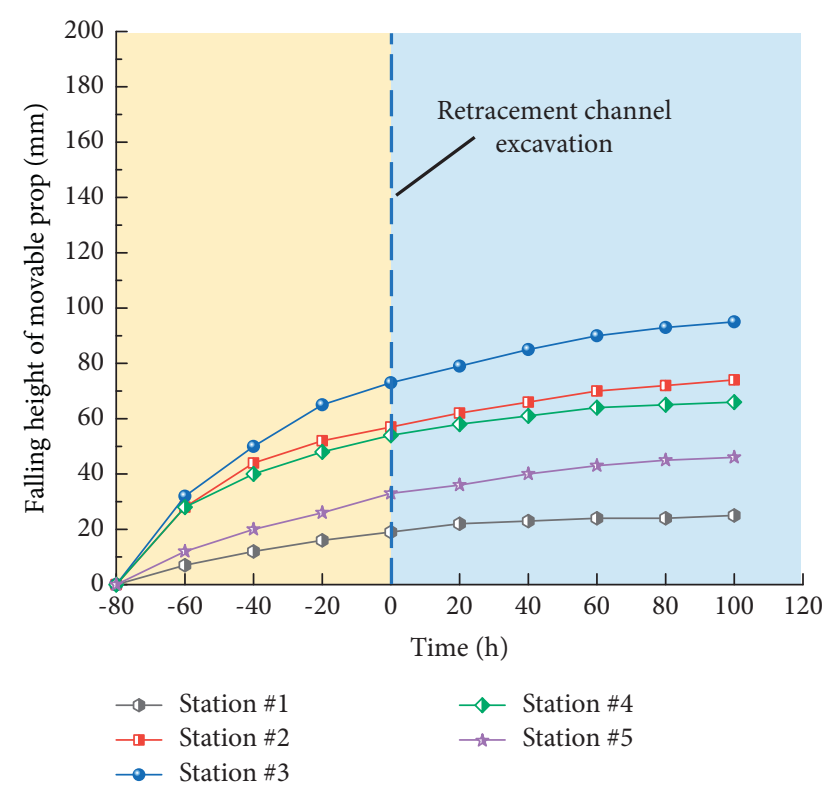

FIGURE 11: The law of the falling height of the movable prop of the hydraulic supports with time.

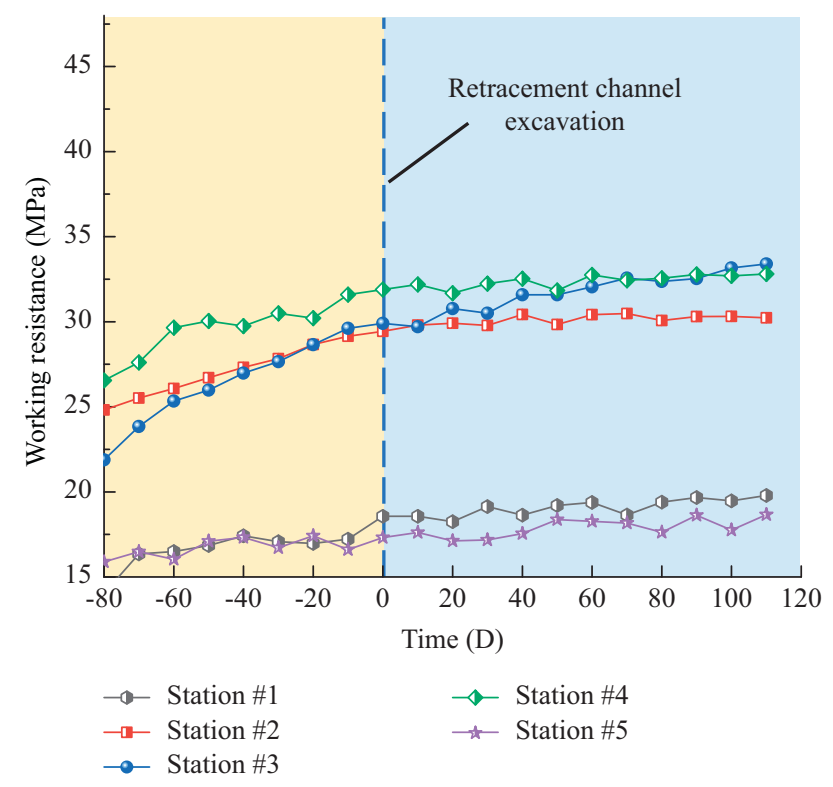

FIGURE 12: The law of the working resistance of hydraulic support with time.

movable prop of station \#5 is the smallest, and $46 \mathrm{~mm}$ was reached before the equipment was retraced. The average falling rate of the movable prop was $0.33 \mathrm{~mm} / \mathrm{h}$, and the maximum rate was $0.48 \mathrm{~mm} / \mathrm{h}$. After the excavation of the retracement channel and before the retracement of the equipment, the average falling rate of the movable prop was $0.13 \mathrm{~mm} / \mathrm{h}$ and the maximum rate was $0.22 \mathrm{~mm} / \mathrm{h}$. This shows that the falling rate of the movable prop decreases and the roof tends to be stable during this period.

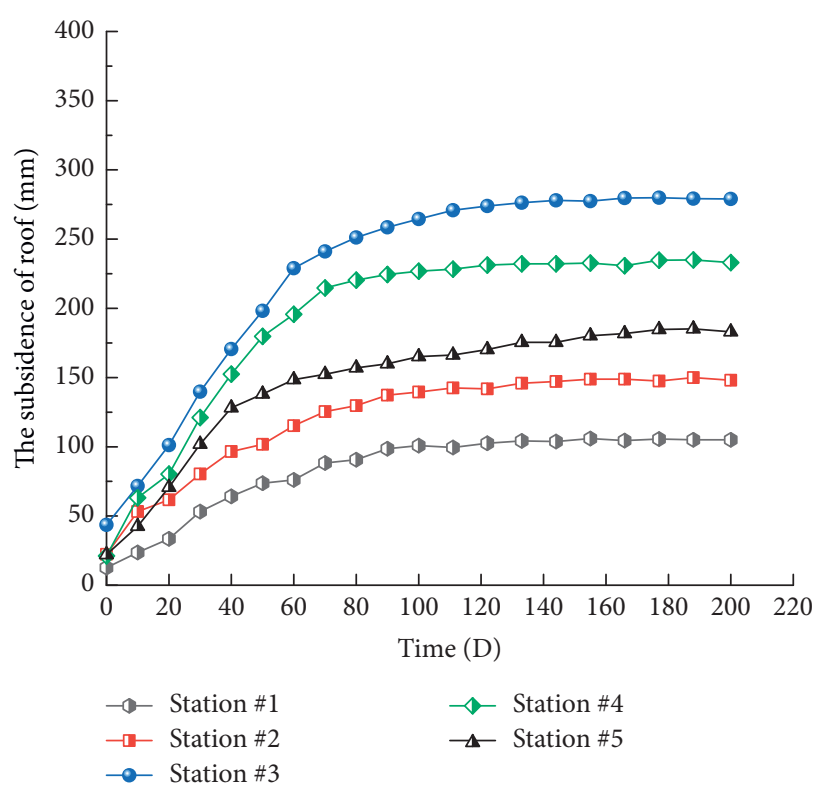

FIgUre 13: The law of the roof subsidence with time.

(2) As shown in Figure 12, the working resistance of the hydraulic support increases with time. In the whole process, the increase in the working resistance of the hydraulic support is very small, and the maximum increase is only 9.2 $\mathrm{MPa}$, the increase is larger in the middle and smaller in the head and tail. Along the working face, the roof is a fixed beam structure at both ends, the bending moment and deflection in the middle are the largest, and the ground pressure behavior is severe.

(3) As shown in Figure 13, the roof subsidence of five stations of excavation for 200 hours was observed, and the cross-point method was adopted. As shown in Figure 13, the roof subsidence increases with time, the average subsidence of the roof is $189.6 \mathrm{~mm}$, the roof subsidence is high in the middle and low in the head and tail, and the maximum roof subsidence is $279 \mathrm{~mm}$ at station $\# 3$.

\section{Conclusions}

(1) The load of the hydraulic support when the main roof fracture is located above the gob, above the hydraulic support, above the retracement channel, and above the solid coal were analyzed and compared. When the fracture of the main roof is located above the gob, the sinking rotation angle of the immediate roof is 0 and the working resistance of the hydraulic support is minimum.

(2) Sublevel excavation technology of the retracement channel is proposed, and the roof vertical stress, roof vertical displacement, roof principal stress difference, and coal rib deformation of surrounding rock with different excavation technologies are compared by numerical simulation. It is proven that sublevel 
excavation technology can improve the stability of surrounding rock more effectively.

(3) In the field application, the maximum falling height of the movable prop of the hydraulic supports is $152 \mathrm{~mm}$, the maximum falling rate is $0.48 \mathrm{~mm} / \mathrm{h}$, the maximum increase in the working resistance of the hydraulic support is $9.2 \mathrm{MPa}$, and the maximum roof subsidence is $189.6 \mathrm{~mm}$. It meets the requirements of safe and rapid retracement of equipment.

\section{Data Availability}

The data used to support the findings of this study are included within the article.

\section{Conflicts of Interest}

The authors declare that there are no conflicts of interest regarding the publication of this article.

\section{Acknowledgments}

This work was supported by the National Natural Science Foundation of China (no. 51974317), Yue Qi Distinguished Scholar Project (no. 800015Z1138), China University of Mining and Technology, Beijing, and Fundamental Research Funds for the Central Universities (no. 2020YJSNY03), and Key Science and Technology Program of Henan Province (no. 202102310221).

\section{References}

[1] F. He, K. Lv, X. Li, B. Qin, and L. Li, "Failure mechanism and control of lower retracement channel in close-distance double-thick coal seams," Shock and Vibration, vol. 2021, no. 1, pp. 1-19, 2021.

[2] Z. Chen, Y. Yuan, and C. Zhu, "Stability mechanism and control factors on equipment removal area under "GoafRoof-Coal" structure," Advances in Civil Engineering, vol. 2021, pp. 1-12, 2021.

[3] X. Liu, D. Fan, Y. Tan et al., "Failure evolution and instability mechanism of surrounding rock for close-distance chambers with super-large section in deep coal mines," International Journal of Geomechanics, vol. 21, no. 5, pp. 1-13, 2021.

[4] X. Liu, S. Song, Y. Tan et al., "Similar simulation study on the deformation and failure of surrounding rock of a large section chamber group under dynamic loading," International Journal of Mining Science and Technology, vol. 31, no. 3, pp. 495-505, 2021.

[5] J. Wang, J.-G. Ning, Y.-L. Tan, S.-C. Hu, and W.-Y. Guo, "Deformation and failure laws of roadway surrounding rock and support optimization during shallow-buried multi-seam mining," Geomatics, Natural Hazards and Risk, vol. 11, no. 1, pp. 191-211, 2020.

[6] M. Xingen, H. Manchao, W. Yajun, Z. Yong, Z. Jiabin, and L. Yuxing, "Study and application of roof cutting pressure releasing technology in retracement channel roof of Halagou 12201 working face," Mathematical Problems in Engineering, vol. 2018, pp. 1-15, 2018.

[7] Y. Chen, S. Q. Ma, and Y. Yu, "Stability control of underground roadways subjected to stresses caused by extraction of a 10-m-Thick coal seam: a case study," Rock Mechanics and Rock Engineering, vol. 50, pp. 1-10, 2017.

[8] B. Wang, F. Dang, W. Chao, Y. Miao, J. Li, and F. Chen, "Surrounding rock deformation and stress evolution in predriven longwall recovery rooms at the end of mining stage," International Journal of Coal Science \& Technology, vol. 6, no. 4, pp. 536-546, 2019.

[9] X. Zhang, P. Gong, K. Wang, J. Li, and Y. Jiang, "Characteristic and mechanism of roof fracture ahead of the face in an ltcc panel when passing an abandoned roadway: a case study from the Shenghua coal mine, China," Rock Mechanics and Rock Engineering, vol. 52, no. 8, pp. 2775-2788, 2019.

[10] Y. P. Qin, Y. P. Song, W. Liu, and W. Duo, "Spatiotemporal evolution of coal spontaneous combustion in longwall gobs: a case study from mining discontinuation to resumption," Energy Science \& Engineering, vol. 9, pp. 710-723, 2021.

[11] F. Liu and Z. X. Jiang, "Research on deformation mechanism of retracement channel during fully mechanized caving mining in superhigh seam," Advances in Civil Engineering, vol. 2018, pp. 1-13, 2018.

[12] Z. Xia, Q. L. Yao, G. S. Meng et al., "Numerical study of stability of mining roadways with $6.0-\mathrm{m}$ section coal pillars under influence of repeated mining," International Journal of Rock Mechanics and Mining Sciences, vol. 138, pp. 1-16, 2021.

[13] H. S. Jia, L. Y. Wang, K. Fan, B. Peng, and K. Pan, "Control technology of soft rock floor in mining roadway with coal pillar protection: a case study," Energies, vol. 12, pp. 1-21, 2019.

[14] X. Guo, Z. Zhao, X. Gao, X. Wu, and N. Ma, "Analytical solutions for characteristic radii of circular roadway surrounding rock plastic zone and their application," International Journal of Mining Science and Technology, vol. 29, no. 2, pp. 263-272, 2019.

[15] C. Li, Z. Wu, W. L. Zhang et al., "A case study on asymmetric deformation mechanism of the reserved roadway under mining influences and its control techniques," Geomechanics and Engineering, vol. 22, pp. 449-460, 2020.

[16] S. Xie, Q. Zhang, D. Chen et al., "Research of roof anchorage rock beam bearing structure model of extra-large width openoff cut and its engineering application in a coal mine, China," Advances in Civil Engineering, vol. 2020, pp. 1-19, 2020.

[17] D. Chen, Q. Zhang, S. Xie et al., "Combined support technology for main roadway passing through goaf: a case study," Energy Science \& Engineering, vol. 8, no. 11, pp. 3925-3941, 2020.

[18] X. Li, M. Ju, Q. Yao, J. Zhou, and Z. Chong, "Numerical investigation of the effect of the location of critical rock block fracture on crack evolution in a gob-side filling wall," Rock Mechanics and Rock Engineering, vol. 49, no. 3, pp. 1041-1058, 2016.

[19] H. P. Kang, J. Lin, and M. J. Fan, "Investigation on support pattern of a coal mine roadway within soft rocks - a case study," International Journal of Coal Geology, vol. 140, pp. 31-40, 2015.

[20] B. Wu, X. Wang, J. Bai, W. Wu, X. Zhu, and G. Li, "Study on crack evolution mechanism of roadside backfill body in gobside entry retaining based on UDEC trigon model," Rock Mechanics and Rock Engineering, vol. 52, no. 9, pp. 33853399, 2019.

[21] Z. Li, J. Xu, J. Ju, and W. Zhu, “The effects of the rotational speed of voussoir beam structures formed by key strata on the ground pressure of stopes," International Journal of Rock Mechanics and Mining Sciences, vol. 108, pp. 67-79, 2018. 
[22] Y. B. Hou, S. S. He, D. Q. Zhou et al., "Analysis of overburden structure and support working resistance of working face in fully-mechanized top coal caving with large mining height in ultra-thick coal seam," Journal of Mining Science and Technology, vol. 2, pp. 42-48, 2017.

[23] Z. B. Cheng, D. Z. Kong, and J. H. Yang, "The breaking characteristics of thick-hard roof and determination of support capacity in fully mechanized caving face," Journal of Mining Science and Technology, vol. 1, no. 2, pp. 172-180, 2016.

[24] K. Yang, X. Chi, W. Liu, L. Dou, and Z. Wei, "Strong ground pressure mechanism and control at the longwall top coal caving with a single key stratum in goaf," Shock and Vibration, vol. 2020, pp. 1-12, 2020.

[25] Y. Yuan, S. Tu, and X. Zhang, "System dynamics model of the support-surrounding rock system in fully mechanized mining with large mining height face and its application," International Journal of Mining Science and Technology, vol. 23, no. 6, pp. 879-884, 2013.

[26] A. Batugin, Z. Q. Wang, Z. H. Su, and S. S. Sidikovna, "Combined support mechanism of rock bolts and anchor cables for adjacent roadways in the external staggered splitlevel panel layout," International Journal of Coal Science and Technology, vol. 8, no. 4, pp. 659-673, 2021.

[27] J. Y. Qiao, Complex Dynamics of Renormalization TransformationsScience Press, Beijing, China, 2010.

[28] M. G. Qian, X. X. Miao, F. L. He et al., "Study on coupling mechanism between hydraulic support and surrounding rock of stope," Journal of China Coal Society, vol. 1, pp. 40-44, 1996.

[29] M. F. Cai, M. C. He, and D. Y. Liu, Rock Mechanics and EngineeringScience Press, Beijing, China, 2013.

[30] X. H. Xu, F. L. He, X. B. Li et al., "Research on mechanism and control of asymmetric deformation of gob side coal roadway with fully mechanized caving mining," Engineering Failure Analysis, vol. 120, pp. 1-12, 2021. 